\title{
ENTENDIENDO LOS CONCEPTOS CONSTITUCIONALES DE LIBRE INICIATIVA PRIVADA Y ECONOMÍA SOCIAL DE MERCADO
}

\author{
LUIS FELIPE VELARDE KOECHLIN* \\ Universidad de Lima, Lima, Perú \\ Ifvelard@ulima.edu.pe \\ Recibido: 15/11/2020 Aprobado: 22/11/2020 \\ doi: https://doi.org/10.26439/iusetpraxis2021.n052.4966
}

\begin{abstract}
RESUMEN. El presente trabajo busca explicar, de manera sencilla y graficando en forma general, la adecuada aplicación del concepto de libre iniciativa privada, junto con el de economía social de mercado, los cuales fueron recogidos por los principios generales del régimen económico de la Constitución Política del Perú de 1993. Se explican los efectos de un libre mercado complementado con el modelo de justicia social y los alcances de la intervención (o no) del Estado, a fin de conseguir un mejor precio y calidad de producto a favor de los consumidores o usuarios de los bienes y servicios. Así es posible velar por los intereses de estos últimos y equilibrar la asimetría de información entre la oferta y la demanda. Asimismo, se añade una explicación sobre los principios de libertad de empresa y libertad de trabajo, pluralismo económico, principio de subsidiariedad, libre competencia, protección al consumidor, libertad de contratar y libre tenencia de moneda (divisas).
\end{abstract}

PALABRAS CLAVE: libre iniciativa privada / economía social de mercado / libre mercado / libre competencia

\footnotetext{
* Abogado por la Universidad de Lima. Máster en Derecho Empresarial por la Universidad de Lima, con doble grado por la Universidad Autónoma de Madrid (UAM). Socio del Estudio Ramírez Abogados. Profesor del curso de Derecho Comercial I en la Facultad de Derecho de la Universidad de Lima.
} 


\section{UNDERSTANDING THE CONSTITUTIONAL CONCEPTS OF FREE PRIVATE INITIATIVE AND SOCIAL MARKET ECONOMY}

ABSTRACT. The present paper seeks to explain, in a simple and general way, the adequate application of the concepts of free private initiative and social market economy, collected from the general principles of the economic system of the 1993 Political Constitution of Peru. The effects of a free market complemented with the model of social justice and the scope of the intervention (or lack of intervention) of the State are explained to achieve a better price and quality of the products in favor of the consumers or users of the goods and services. Thus, it is possible to ensure their interests and balance the asymmetry of information between supply and demand. In addition, this analysis is complemented with an explanation of the principles of free enterprise and freedom to work, economic pluralism, principle of subsidiarity, free competition, consumer protection, freedom of contract and free possession of currency (foreign exchange holdings).

KEYWORDS: free private initiative / social market economy / free market / free competition 


\section{INTRODUCCIÓN}

En un día de clases ordinario, estábamos discutiendo con alumnos de pregrado sobre el caso de salas de cine que restringieron a sus clientes la alternativa de ingresar con sus comestibles propios, en vez de adquirir los productos alimenticios que ofertaban con precios hasta cinco veces mayores en comparación con otros establecimientos comerciales. 0 también sobre la concertación de precios dirimida por el Tribunal del Instituto Nacional de Defensa de la Competencia y de la Protección de la Propiedad Intelectual (Indecopi) cuando se implementó el Seguro Obligatorio de Accidentes de Tránsito (SOAT) en la legislación peruana. 0 el caso difundido por los medios de comunicación con respecto a una concertación de precios en los medicamentos comercializados por algunas farmacéuticas privadas. Incluso conversamos sobre el decreto de urgencia publicado en el año 2019 que estableció el control de fusiones. Caímos en la cuenta de que estos casos tienen denominadores en común: la libre iniciativa privada y la economía social de mercado dispuestas en los principios generales del régimen económico regulados en el Capítulo I del Título III de nuestra Constitución Política del Perú de 1993.

Por ello, el presente artículo tiene como objeto esclarecer conceptos como el de libre iniciativa privada y economía social de mercado, los cuales han sido pilares para nuestro sistema jurídico moderno y nuestro desarrollo económico actual. Además, la presente explicación busca ser realizada de manera sencilla, porque buscamos ir de la mano con la siguiente frase que circula actualmente en las redes sociales: "Si no lo puedes explicar de manera sencilla, es que no lo has entendido bien".

\section{SOBRE EL LIBRE MERCADO Y SUS EFECTOS EN LA ECONOMÍA}

Antes de entrar a analizar los conceptos de libre iniciativa privada y economía social de mercado, contemplados en los principios generales del régimen económico de la Constitución Política del Perú de 1993 (en adelante, la Constitución), es sustancial tener una noción del libre mercado y cuáles son sus efectos en la economía de un país.

Si bien podemos considerar al libre mercado como un sistema económico basado en la libertad de la oferta y la demanda - es decir, sin la intervención del Estado-, la importancia de dicho modelo radica en sus resultados, como, por ejemplo, la determinación de los precios; las decisiones de producción, inversión o ahorro que tomen los agentes de la oferta con respecto a las ganancias o utilidades por obtener; o las decisiones de consumo que tomen los agentes de la demanda con respecto a la abundancia o escasez de los productos o servicios que se ofrezcan en el mercado.

Para explicarlo en términos mucho más simples - para no economistas-, vamos a realizar un ejercicio comparativo entre un modelo de libre mercado contra un modelo de regulación de precios. Por favor, es importante tener en cuenta que este ejemplo es 
para fines didácticos y es puramente general. Consideremos que todo mercado tiene sus excepciones y particularidades, y estas reglas no son aplicables a todos los productos, servicios, industrias, mercados, comunidades, sociedades o países.

\section{El concepto de elasticidad de la demanda y la variación de precios}

Como primer punto, tengamos en cuenta que el mercado es un lugar teórico - que puede ser un lugar físico o virtual- en el cual la oferta y la demanda determinan los precios de los bienes y servicios intercambiados. Para simplificar nuestro ejemplo, vamos a referirnos solamente al intercambio de bienes (productos).

Ahora bien, grafiquemos, en este ejemplo, a la oferta como la cantidad de bienes que los empresarios están dispuestos a vender a cierto precio. Por otro lado, grafiquemos a la demanda como la cantidad de bienes que los consumidores están dispuestos a adquirir a ese precio.

Considerando que en un modelo de libre mercado el Estado no interviene en el mercado ni fija los precios, ¿qué sucedería si el precio de un producto es muy alto? Simplemente, no todos los consumidores van a poder pagar ese precio tan alto, lo que genera que la oferta sea mayor que la demanda, o que la demanda sea menor que la oferta. En cambio, ¿qué sucedería si el precio es muy bajo? La demanda será mucho mayor que la oferta, o la oferta será mucho menor que la demanda, lo que genera un caso extremo en que no todos los consumidores puedan adquirir el producto deseado, porque se va a agotar. Por este motivo, en el ejemplo descrito, los precios llegan a un punto de equilibrio, a un precio de mercado conocido por ambos agentes - tanto por la oferta como por la demanda-, logrando cierta simetría para el abastecimiento de los productos.

Así, la interacción entre la oferta y la demanda será la encargada de determinar los precios, porque si la oferta de un producto aumenta, evidentemente el precio tenderá a bajar, porque el producto será muy abundante. De otro lado, si la oferta de un producto disminuye, el producto escaseará, por lo que su precio subirá al ser demandado por la misma cantidad - o tal vez más-de consumidores.

Con la demanda sucede una regla similar, porque si la demanda se incrementa, el precio subirá, dado que más consumidores buscarán el mismo producto y este se volverá más escaso. En cambio, si la demanda disminuye, menos consumidores desearán el mismo producto, lo que genera un exceso de este o de su oferta y el precio tiende a bajar.

Lo expuesto es lo que económicamente se conoce como la elasticidad de la demanda de un producto. Si sube el precio de un producto y su demanda baja, dicho producto es elástico. Por el contrario, si sube el precio de un producto, pero su demanda no varía, el producto es inelástico, por ejemplo, el agua - que es esencial para vivir-, la insulina para personas diabéticas, el gas natural y otros productos que no tengan o tengan muy 
pocos sustitutos. Para fines de este ejemplo, vamos a partir de la base de un producto elástico.

\title{
El concepto de ganancia y margen de ganancia
}

Es importante comprender otro concepto: la ganancia. Para ello, tengamos en cuenta la fórmula más simple de composición de un estado de ganancias y pérdidas o estado de resultados de una empresa:

\author{
Ingreso por ventas \\ (menos) Costo del producto \\ (menos) Gastos de la operación
}

\section{Utilidad/ganancia}

El costo es el egreso imputable directamente a la adquisición y/o fabricación del producto que la empresa comercializa. Por ejemplo, ¿cuánto le costó a la empresa adquirir la materia prima y fabricar el producto?, o ¿cuánto le costó a la empresa adquirir directamente el producto para revenderlo a un precio más alto?

El gasto es el egreso que no se puede imputar directamente a la adquisición y/o fabricación del producto que la empresa vende, sino que más bien está vinculado con la operación o el desarrollo del negocio. Por ejemplo, el pago de la luz, el alquiler del local, los sueldos de los trabajadores, entre otros similares.

En ese sentido, la diferencia entre el precio de venta - que implica los ingresos por las ventas- menos los costos y los gastos genera como resultado la utilidad o la ganancia para la empresa.

Lo lógico es que una empresa logre tener bajos costos de adquisición o producción y bajos gastos, y así obtenga altas ganancias con base en el precio de mercado determinado por la libre oferta y demanda. A primera impresión, podría parecer que la empresa "está teniendo muchas ganancias". Pero, si lo vemos desde un punto de vista "macro" o país, podremos percibir que, aunque se venda al mismo precio de mercado, otras empresas que ingresen a competir al mercado con costos de producción y/o gastos menos eficientes o más altos, aún tendrán un margen de ganancia, lo que incentivará un incremento de la oferta.

Para representarlo mejor, en la figura 1, se observa un ejemplo de cuatro empresas con dos columnas cada una. La columna de la izquierda es el precio del producto en la cantidad de 4,0, y la columna de la derecha son los costos y gastos totales de cada empresa de $0,5,3,0,2,0$ y 1,5 , respectivamente. 


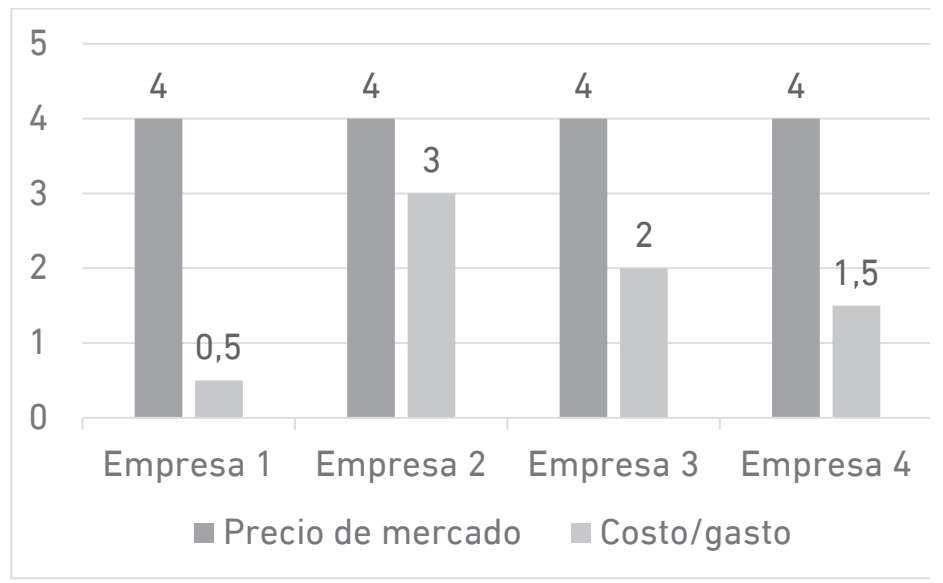

Figura 1. Ingresos por ventas vs. costos y gastos de cuatro empresas en libre mercado

Elaboración propia

Si bien la Empresa 1 ha logrado tener menores costos y gastos y, por tanto, obtiene mayores márgenes de ganancia, bajo el mismo precio de mercado todavía pueden ingresar otros competidores a ofertar. Estas otras tres empresas tendrán costos y gastos más altos, pero igual conseguirán un margen de ganancia.

El hecho de que aparezcan nuevos competidores implicará, indefectiblemente, un incremento de la oferta. El aumento de competidores en la oferta genera, en consecuencia, una disminución de los precios hacia la demanda. De hecho, con una sana competencia entre los mismos agentes de la oferta, las empresas "pelearán" para brindarle una mejor calidad de producto y/o servicio a los consumidores, aunque sea al mismo o a un menor precio.

\section{Caso contrario: el modelo de regulación de precios}

Yéndonos al modelo antagónico, ¿qué sucedería con un modelo de regulación de precios? Usando el mismo ejemplo de un producto elástico, cuando el Estado regula o "fija" un menor precio para toda la oferta, está determinando cuánto es el margen de ganancia con el cual la oferta debe beneficiarse.

Sin embargo, al tener un menor precio de venta, como efecto colateral muchas empresas - generalmente las pequeñas, que tienen costos y gastos más altos- no podrán competir contra otras empresas que tienen costos y gastos abaratados; y, por tanto, dejarían de comercializar el bien en el mercado, disminuyendo así la oferta. 
Para representarlo mejor, retomaremos el ejemplo de la figura 1, donde aparecen cuatro empresas con dos columnas cada una, pero, en este caso, la columna de la izquierda tendrá como precio del producto la cantidad regulada de 1,0, y las columnas de la derecha tendrán como costos y gastos totales de cada empresa las mismas cantidades de 0,5, 3,0, 2,0 y 1,5, respectivamente (véase la figura 2).

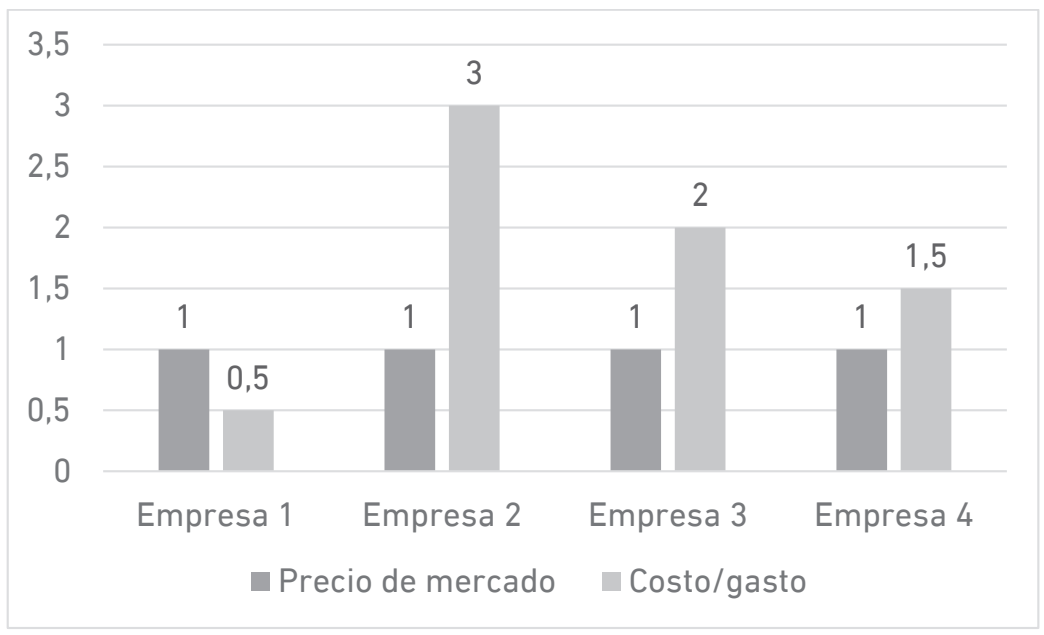

Figura 2. Ingresos por ventas vs. costos y gastos de cuatro empresas con precios regulados

Elaboración propia

Es evidente, en este ejemplo, que la Empresa 1 sería la única que obtendría margen de ganancia por sus bajos costos y gastos, mientras que las otras empresas arrojarían pérdidas por sus altos costos y gastos, viéndose obligadas a retirarse del mercado, con lo que disminuiría el número de agentes en la oferta. Al disminuir la oferta, el efecto natural es que el precio se incremente. No obstante, al estar regulado y no poder incrementarse, un efecto natural es que la demanda aumente y el producto comience a escasear.

La historia de nuestro país en décadas anteriores y la de otros países en el presente milenio nos han demostrado que, ante la escasez, surgen los "mercados negros", que son mercados paralelos que buscarán suplir la falta de la oferta, pero con precios mucho más altos. Además, la experiencia (no tan) reciente también ha demostrado que un incremento en las remuneraciones mínimas vitales podría ayudar a la población a adquirir más bienes, aunque la realidad es que la demanda continuará incrementándose y la adquisición de productos será inviable. 
Por ello, nuestra Constitución optó por un modelo de libre mercado -combinado con la justicia social一, en el que el Estado no dirige la actividad económica, aunque genera la seguridad jurídica para que la oferta y la demanda la ejerzan libremente.

\section{SOBRE LA INICIATIVA PRIVADA Y LA ECONOMÍA SOCIAL DE MERCADO}

El primer principio general del régimen económico de nuestra Constitución se fundamenta en dos conceptos: la libre iniciativa privada y la economía social de mercado.

Artículo 58.- Economía social de mercado

La iniciativa privada es libre. Se ejerce en una economía social de mercado. Bajo este régimen, el Estado orienta el desarrollo del país, y actúa principalmente en las áreas de promoción de empleo, salud, educación, seguridad, servicios públicos e infraestructura.

¿Qué entendemos por "libre iniciativa privada"? A tal efecto, el Tribunal Constitucional peruano ha precisado en el análisis de su Sentencia del Pleno de fecha 6 de junio del 2005 recaída en el Expediente N. ${ }^{\circ} 0001-2005-P I / T C ~(2005)$ lo siguiente:

44. Así, este Tribunal ha establecido que otro principio que informa a la totalidad del modelo económico es el de la libre iniciativa privada, prescrito en el artículo 58 de la Constitución y que se encuentra directamente conectado con lo establecido en el inciso 17) del artículo 2 del mismo texto, el cual consagra el derecho fundamental de toda persona a participar, ya sea en forma individual o asociada, en la vida económica de la Nación. De ello se colige que toda persona natural o jurídica tiene derecho a emprender y desarrollar, con autonomía plena, la actividad económica de su preferencia, afectando o destinando bienes de cualquier tipo a la producción y al intercambio económico con la finalidad de obtener un beneficio o ganancia material. La iniciativa privada puede desplegarse libremente en tanto no colisione los intereses generales de la comunidad, los cuales se encuentran resguardados por una pluralidad de normas adscritas al ordenamiento jurídico; vale decir, por la Constitución, los tratados internacionales y las leyes sobre la materia.

Dicho en otras palabras, la libre iniciativa privada significa que los privados pueden entrar en forma libre a realizar actividad económica, formando parte de la oferta en un mercado.

De otro lado, ¿qué entendemos por una economía social de mercado? Para consignarlo en palabras simples, Paz (2019) describe a la economía social de mercado como

[...] un sistema económico que combina la necesidad de libertad económica con la justicia social. Este sistema reconoce que un mercado altamente eficiente, que satisface todas las necesidades de una sociedad, no es suficiente. Le atribuye al Estado el derecho y la obligación de intervenir cuando se produzca una pérdida de intereses sociales legítimos reconocidos. (párr. 1) 
Como veremos más adelante, y en forma complementaria con el texto del artículo 59 de la Constitución, el modelo de economía social de mercado significa la aplicación de un libre mercado como regla general y, excepcionalmente, el Estado regulará determinados sectores que, por su importancia o trascendencia, deben ser regulados o supervisados, como los servicios públicos, por ejemplo.

Prueba de lo expuesto es la existencia de instituciones como Osiptel, que es el regulador de las telecomunicaciones; Sunass, que es el regulador del servicio de agua potable; y Osinergmin, que es el organismo supervisor de la inversión en energía y minería; entre otros. Si revisamos el último enunciado del artículo 58 de la Constitución, observaremos que el Estado orienta el desarrollo del país hacia las áreas de salud, educación, servicios públicos, infraestructura, empleo y seguridad (social y ciudadana).

Culminaremos indicando que la característica central de una economía social de mercado "no es una cuestión política en absoluto, no es socialista ni capitalista, es simplemente sentido común", tal como citó García Toma (1998, p. 121) a lord Beveridge.

\section{SOBRE LA LIBERTAD DE EMPRESA Y LA LIBERTAD DE TRABAJO}

Como indicamos en los párrafos anteriores, el artículo 59 es el complemento necesario para una correcta aplicación de la libre iniciativa privada y la economía social de mercado:

Artículo 59.- Rol económico del Estado

El Estado estimula la creación de riqueza y garantiza la libertad de trabajo y la libertad de empresa, comercio e industria. El ejercicio de estas libertades no debe ser lesivo a la moral, ni a la salud, ni a la seguridad públicas. El Estado brinda oportunidades de superación a los sectores que sufren cualquier desigualdad; en tal sentido, promueve las pequeñas empresas en todas sus modalidades.

A mayor abundamiento, el Tribunal Constitucional también ha precisado en el análisis de su Sentencia del Pleno de fecha 6 de junio del 2005 recaída en el Expediente N. ${ }^{\circ} 0001-$ 2005-PI/TC (2005) lo siguiente:

45. Por otra parte, la libertad de empresa, consagrada por el artículo 59 de la Constitución, se define como la facultad de poder elegir la organización y efectuar el desarrollo de una unidad de producción de bienes o prestación de servicios, para satisfacer la demanda de los consumidores o usuarios. Tiene como marco una actuación económica autodeterminativa, lo cual implica que el modelo económico social de mercado será el fundamento de su actuación y, simultáneamente, le impondrá límites a su accionar. Consecuentemente, dicha libertad debe ser ejercida con sujeción a la ley - siendo sus limitaciones básicas aquellas que derivan de la seguridad, la higiene, la moralidad o la preservación del medio ambiente-, y su ejercicio deberá respetar los diversos derechos de carácter socioeconómico que la Constitución reconoce. 
Del texto expuesto en el artículo 59 de nuestra Constitución, y de la descripción otorgada por el ente encargado de interpretarla, concluimos que nuestro régimen económico constitucional complementa la sola mención de la libre iniciativa privada y la economía social de mercado con los siguientes pilares:

a. Se estimula la creación de riqueza, hecho que motiva a las personas - sean naturales o jurídicas - para emprender una actividad. De hecho, la acumulación de riqueza es un acto que, a corto, mediano o largo plazo, nos permite la generación del capital.

b. Existe libertad para crear empresa; es decir, existe libertad para organizar tanto el capital — producto de la acumulación de riqueza - como el trabajo, garantizándose también la libertad en este último elemento.

c. Se permite la libertad de comercio e industria, dejando la puerta abierta para que los agentes de la oferta puedan acceder al mercado y puedan emprender las actividades económicas que satisfagan las necesidades de los consumidores, siempre y cuando estas actividades sean legales, lícitas, no atenten contra la moral ni la seguridad pública, evidentemente.

d. Existe una libertad para ejercer empresa conforme a ley, bajo las modalidades que la ley provee, por ejemplo, los tipos societarios. La encontraremos descrita en el artículo 60 de la Constitución.

e. Encontraremos, también, una libertad para competir, dispuesta en el artículo 61 de la Constitución.

f. Existe también una libertad para cesar la empresa, la cual, si bien no está descrita expresamente en los principios generales del régimen económico, se encuentra amparada por el Tribunal Constitucional en el análisis de su Sentencia del Pleno de fecha 6 de junio del 2005 recaída en el Expediente N. ${ }^{\circ} 0001-2005-\mathrm{PI} /$ TC (2005), anteriormente descrita.

\section{PLURALISMO ECONÓMICO Y PRINCIPIO DE SUBSIDIARIEDAD}

Ahora bien, ¿es suficiente con los artículos anteriormente descritos para que funcione de manera adecuada la libre iniciativa privada y la economía social de mercado? A nuestro parecer, no. Este criterio también fue recogido por la Constitución, al complementar el pluralismo económico y el principio de subsidiariedad en su artículo 60:

Artículo 60.- Pluralismo económico

El Estado reconoce el pluralismo económico. La economía nacional se sustenta en la coexistencia de diversas formas de propiedad y de empresa. 
Solo autorizado por ley expresa, el Estado puede realizar subsidiariamente actividad empresarial, directa o indirecta, por razón de alto interés público o de manifiesta conveniencia nacional.

La actividad empresarial, pública o no pública, recibe el mismo tratamiento legal.

Como se puede observar, el Estado reconocerá la coexistencia de múltiples modalidades económicas y/o empresas, lo que implica que reconocerá también las diferencias entre determinados tipos de empresa. Por ejemplo, bajo la redacción del artículo 59 de la Constitución, el Estado promueve a la pequeña empresa "en todas sus modalidades"; bajo el texto del artículo 61, la Constitución reconoce los monopolios, aunque combate el abuso de su posición dominante; o, bajo la redacción del artículo 62, el Estado puede otorgar garantías y seguridades a determinados tipos de inversiones.

Sin perjuicio de ello, el elemento enriquecedor para la materia del presente artículo es el principio de subsidiariedad contemplado en el segundo párrafo del artículo 60 de la Constitución, dado que, de acuerdo con este principio, el Estado peruano no puede ejercer actividad empresarial como regla general.

La lógica de este principio es evidente si la enlazamos con el concepto de libre mercado explicado en los párrafos anteriores: si los agentes de la oferta llegan a un punto de equilibrio con la demanda y obtienen un margen de ganancia considerando un determinado precio de mercado, el ingreso del Estado como un competidor más -como un ofertante más-generaría una distorsión en el mercado.

Tengamos en cuenta que el término subsidio supone una ayuda económica que una persona o entidad de un organismo - generalmente, el Estado- otorga a las personas para satisfacer una necesidad determinada, como, por ejemplo, los subsidios por desempleo que otorgan los Estados de distintos países.

Por ello, la intervención del Estado como agente en la oferta implicaría una distorsión en el mercado, dado que cubriría sus costos y gastos con fondos públicos, por lo que sería una actividad subsidiada. Resulta clara la prohibición, como regla general, de que el Estado intervenga como agente en el mercado y realice actividad económica. Tengamos en cuenta que este sí realiza actividades de carácter económico, como la recaudación de impuestos o la protección de una libre competencia; en este caso de análisis, el Estado solamente va a evitar competir con una "ventaja" sobre los demás agentes de la oferta en un supuesto de libre mercado.

Sin embargo, existe una excepción a la regla: cuando se deba proteger el interés general, la conveniencia nacional o similares, el Estado puede realizar actividad empresarial en forma subsidiada. Esta excepción va de la mano con una economía social de mercado, a diferencia de un libre mercado sin excepciones. 


\section{LIBERTAD Y OBLIGACIÓN DE COMPETIR}

Si bien afirmamos en párrafos anteriores la existencia de una libertad para competir, revisando el desarrollo del artículo 61 de la Constitución, podemos observar que la competencia vendría a ser una obligación, dado que, tal como se complementa con el artículo 65 , una competencia continua, sana y leal genera un beneficio a favor de los consumidores.

Artículo 61.- Libre competencia

El Estado facilita y vigila la libre competencia. Combate toda práctica que la limite y el abuso de posiciones dominantes o monopólicas. Ninguna ley ni concertación puede autorizar ni establecer monopolios.

La prensa, la radio, la televisión y los demás medios de expresión y comunicación social; y, en general, las empresas, los bienes y servicios relacionados con la libertad de expresión y de comunicación, no pueden ser objeto de exclusividad, monopolio ni acaparamiento, directa ni indirectamente, por parte del Estado ni de particulares.

Como concluimos en nuestro ejemplo sobre libre mercado, la competencia - continua, sana y leal- termina generando un beneficio a favor de la demanda, ya sea en un menor precio del mercado, porque, a mayor oferta, disminuye el precio; o porque los consumidores tendrán más opciones para escoger y los ofertantes se verán obligados a mejorar la calidad de sus productos o servicios para que los consumidores los adquieran. Evidentemente, si bien el Estado no cumple un rol regulador, sí tiene un rol supervisor a través del Instituto Nacional de Defensa de la Competencia y de la Protección de la Propiedad Intelectual (Indecopi).

Ahora bien, a diferencia de la Constitución anterior, la Constitución actual no prohíbe el monopolio, dado que este es una consecuencia de un sistema económico que permite la acumulación de riqueza. De hecho, es natural que la competencia entre ofertantes genere que cada uno de ellos busque como meta final el monopolio. No obstante, nuestra Constitución prohíbe dos conductas: el abuso de la posición de dominio y las prácticas restrictivas o limitativas de la libre competencia.

Tales conductas se encuentran reguladas en el Decreto Legislativo N. ${ }^{\circ} 1034$, que aprueba la Ley de Represión de Conductas Anticompetitivas. En ellas se sanciona no el hecho de obtener la posición de dominio, sino la conducta de "abusar" de tal posición, así como también toda práctica que restrinja y/o limite la libre competencia.

\section{PROTECCIÓN AL CONSUMIDOR}

A efectos de equilibrar la asimetría de información y de posiciones entre el consumidor promedio y los agentes de la oferta, nuestra Constitución busca defender, al amparo de su artículo 65, los intereses de los consumidores y usuarios. 
Artículo 65.- Protección al consumidor

El Estado defiende el interés de los consumidores y usuarios. Para tal efecto garantiza el derecho a la información sobre los bienes y servicios que se encuentran a su disposición en el mercado. Asimismo, vela, en particular, por la salud y la seguridad de la población.

En tiempos actuales, la labor de protección de los intereses de los consumidores y usuarios del Estado a través del Indecopi se torna evidente. Como prueba de ello, contamos con un Código de Protección y Defensa del Consumidor, que contempla normativa bastante asertiva, aunado a una eficiente actuación tanto orientativa, resolutiva, como fiscalizadora del Indecopi, así como la implementación de los Libros de Reclamaciones físicos y virtuales en los establecimientos. Sin perjuicio de lo expuesto, hay un elemento que no está contemplado en las leyes, pero será materia de análisis en otro trabajo: este es el impacto de las redes sociales en la reputación de los signos distintivos, franquicias, personas jurídicas y grupos de empresas.

Todos estos elementos evidencian que, de la mano con lo dispuesto en el artículo 65 de la Constitución, no solamente existe una adecuada defensa de los intereses de los consumidores y usuarios, sino que también se está equilibrando la asimetría en la información entre ambos agentes. Igualmente, se produce una influencia o control por parte de la demanda hacia la oferta. Esto implica un cambio económico en comparación con lo que sucedía décadas atrás.

\section{SOBRE LA LIBERTAD DE CONTRATAR, INVERSIÓN NACIONAL Y EXTRANJERA, Y LIBRE TENENCIA DE MONEDA}

Los principios contemplados en los artículos 62, 63 y 64 de la Constitución también son pilares importantes para nuestra libre iniciativa privada y economía social de mercado. Por ejemplo, la libertad de contratar garantiza que una norma posterior no modifique un pacto entre privados celebrado con fecha anterior y bajo normas vigentes a dicha fecha de celebración.

Artículo 62.- Libertad de contratar

La libertad de contratar garantiza que las partes pueden pactar válidamente según las normas vigentes al tiempo del contrato. Los términos contractuales no pueden ser modificados por leyes u otras disposiciones de cualquier clase. Los conflictos derivados de la relación contractual solo se solucionan en la vía arbitral o en la judicial, según los mecanismos de protección previstos en el contrato o contemplados en la ley.

Mediante contratos-ley, el Estado puede establecer garantías y otorgar seguridades. No pueden ser modificados legislativamente, sin perjuicio de la protección a que se refiere el párrafo precedente. 
¿Qué sucedería si las partes celebran un contrato de arrendamiento fijando una renta mensual determinada y, posteriormente, el Estado publica una ley que establece un límite máximo de cobro de todas las rentas de los arrendamientos? El resultado sería una clara inseguridad jurídica, que tendría efectos económicos en las inversiones privadas.

Asimismo, en el segundo párrafo del artículo 62 de la Constitución, se previó la posibilidad de que el Estado pueda establecer garantías y otorgar seguridades, generalmente, para las grandes inversiones como los convenios de estabilidad tributaria. Tengamos en cuenta que, económicamente hablando, la seguridad jurídica ayuda a que los inversionistas traigan sus divisas y/o capital a nuestro país, promoviendo el crecimiento económico.

Artículo 63.- Inversión nacional y extranjera

La inversión nacional y la extranjera se sujetan a las mismas condiciones. La producción de bienes y servicios y el comercio exterior son libres. Si otro país o países adoptan medidas proteccionistas o discriminatorias que perjudiquen el interés nacional, el Estado puede, en defensa de este, adoptar medidas análogas.

En todo contrato del Estado y de las personas de derecho público con extranjeros domiciliados consta el sometimiento de estos a las leyes y órganos jurisdiccionales de la República y su renuncia a toda reclamación diplomática. Pueden ser exceptuados de la jurisdicción nacional los contratos de carácter financiero.

El Estado y las demás personas de derecho público pueden someter las controversias derivadas de relación contractual a tribunales constituidos en virtud de tratados en vigor. Pueden también someterlas a arbitraje nacional o internacional, en la forma en que lo disponga la ley.

Artículo 64.- Tenencia y disposición de moneda extranjera

El Estado garantiza la libre tenencia y disposición de moneda extranjera.

Finalmente, la Constitución también busca darle el mismo tratamiento a la inversión nacional que a la inversión extranjera: permite libertad en el comercio exterior (exportaciones e importaciones), así como la libre tenencia y disposición de moneda extranjera (divisa).

\section{CONCLUSIONES}

De lo expuesto, podemos concluir que el modelo constitucional basado en la libre iniciativa privada y economía social de mercado tiene como regla general un libre mercado; es decir que la oferta y la demanda determinen por sí solos el precio del mercado. No obstante, el modelo de justicia social implica una supervisión del Estado para garantizar una continua, sana y leal competencia entre los agentes, a fin de lograr un mejor precio 
y/o calidad de producto a favor de los consumidores o usuarios de los bienes y servicios, velando por los intereses de estos últimos y buscando equilibrar la asimetría de información entre ambos agentes. Excepcionalmente, existen sectores que serán regulados por el Estado, como los servicios públicos y otros en los que el Estado participará en forma razonable, como salud, educación, infraestructura, empleo y seguridad.

\section{REFERENCIAS}

García Toma, V. (1998). Análisis sistemático de la Constitución peruana de 1993 (tomo II). Universidad de Lima, Fondo Editorial.

Paz, N. (29 de noviembre del 2019). Una economía de mercado para todos: retrospectivas y avances de cara al Bicentenario. Stakeholders. Sostenibilidad. Recuperado de https://stakeholders.com.pe/estado/una-economia-mercado-todos-retrospectivas-avances-cara-al-bicentenario

Sentencia del Pleno recaída en el Expediente N. ${ }^{\circ}$ 0001-2005-PI/TC. (2005). Tribunal Constitucional. (2005). Recuperado de https://tc.gob.pe/jurisprudencia/2006 /00001-2005-Al.html 